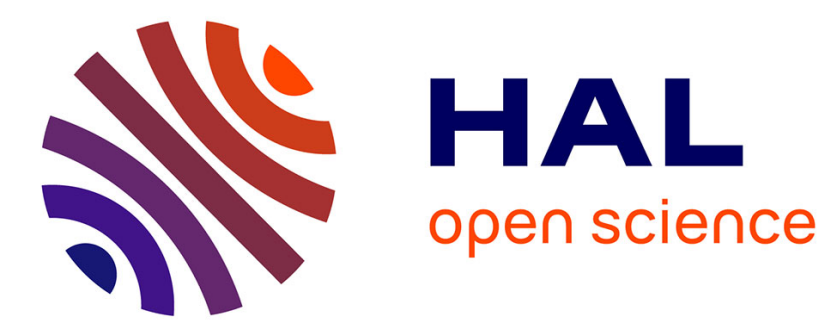

\title{
Fabrication and characterization of Ge-Sb-Se-I glasses and fibers
}

Chen Jiang, Ci Cheng, Qingde Zhu, Xunsi Wang, Qiuhua Nie, Shixun Dai, Guangming Tao, Minming Zhu, Fangxing Liao, Peiqing Zhang, et al.

\section{- To cite this version:}

Chen Jiang, Ci Cheng, Qingde Zhu, Xunsi Wang, Qiuhua Nie, et al.. Fabrication and characterization of Ge-Sb-Se-I glasses and fibers. Applied physics. A, Materials science \& processing, 2015, 120 (1), pp.127-135. 10.1007/s00339-015-9179-z . hal-01162342v2

\section{HAL Id: hal-01162342}

\section{https://hal-univ-rennes1.archives-ouvertes.fr/hal-01162342v2}

Submitted on 14 Sep 2015

HAL is a multi-disciplinary open access archive for the deposit and dissemination of scientific research documents, whether they are published or not. The documents may come from teaching and research institutions in France or abroad, or from public or private research centers.
L'archive ouverte pluridisciplinaire HAL, est destinée au dépôt et à la diffusion de documents scientifiques de niveau recherche, publiés ou non, émanant des établissements d'enseignement et de recherche français ou étrangers, des laboratoires publics ou privés. 


\title{
Fabrication and characterization of Ge-Sb-Se-I glasses and fibers
}

\author{
Chen Jiang ${ }^{1}$, Ci Cheng ${ }^{1}$, Qingde Zhu ${ }^{1}$, Xunsi Wang ${ }^{1, *}$, Qiuhua Nie ${ }^{1}$, Shixun Dai ${ }^{1}$, \\ Guangming Tao ${ }^{2}$, Minming Zhu ${ }^{1}$, Fangxing Liao ${ }^{1}$, Peiqing Zhang ${ }^{1}$, Xiang Shen ${ }^{1}$, Tiefeng \\ $\mathrm{Xu}^{1}$, Peiquan Zhang ${ }^{1}, \mathrm{Ziju}_{\mathrm{ij}} \mathrm{Liu}^{1}$, Xianghua Zhang ${ }^{3}$ \\ ${ }^{l}$ Laboratory of Infrared Material and Devices, Advanced Technology Research Institute, Ningbo University, Ningbo, \\ 315211, China \\ ${ }^{2}$ CREOL, The College of Optics \& Photonics, University of Central Florida, Orlando, FL 32816 United States \\ ${ }^{3}$ Laboratory of glasses and Ceramics, UMR 6226 CNRS-University of Rennes 1, Rennes Cedex 135042, France \\ *Corresponding author: xunsiwang@siom.ac.cngtao@creol.ucf.edu
}

\begin{abstract}
Chalcogenide glasses of the $\mathrm{Ge}_{20} \mathrm{Sb}_{5} \mathrm{Se}_{75-\mathrm{x}} \mathrm{I}_{\mathrm{x}}(\mathrm{x}=0,5,10,15,20$ at \%) system were prepared. This study was performed to examine some Ge-Sb-Se-I glass physical and optical properties, the structural evolution of the glass network, and the optical properties of the infrared glass fibers based on our previous studies. The variation process of the glass physical properties, such as transition temperature, glass density, and refractive index, were investigated from the glass of $\mathrm{Ge}_{20} \mathrm{Sb}_{5} \mathrm{~S}_{75}$ to the $\mathrm{Ge}_{20} \mathrm{Sb}_{5} \mathrm{Se}_{75-\mathrm{x}} \mathrm{I}_{\mathrm{x}}$ glass series. The structural evolutions of these glasses were examined by Raman spectroscopy. The $\mathrm{Ge}_{20} \mathrm{Sb}_{5} \mathrm{Se}_{55} \mathrm{I}_{20}$ composition was selected for the preparation of the IR fiber. The $\mathrm{Ge}_{20} \mathrm{Sb}_{5} \mathrm{Se}_{55} \mathrm{I}_{20}$ glass was purified through distillation, and the intensity of the impurity absorption peaks caused by $\mathrm{Ge}-\mathrm{O}, \mathrm{H}_{2} \mathrm{O}$, and $\mathrm{Se}-\mathrm{H}$ was reduced or eliminated in the purified glasses. Then, $\mathrm{Ge}_{20} \mathrm{Sb}_{5} \mathrm{Se}_{55} \mathrm{I}_{20}$ chalcogenide glass fiber for mid-infrared transmission was fabricated using high-purity materials. The transmission loss of the $\mathrm{Ge}_{20} \mathrm{Sb}_{5} \mathrm{Se}_{55} \mathrm{I}_{20}$ fiber was greatly reduced compared with that of the $\mathrm{Ge}_{20} \mathrm{Sb}_{5} \mathrm{Se}_{75}$ glass fiber. The lowest losses obtained were $3.5 \mathrm{~dB} / \mathrm{m}$ at $3.3 \mu \mathrm{m}$ for $\mathrm{Ge}_{20} \mathrm{Sb}_{5} \mathrm{Se}_{75} \mathrm{I}_{20}$ fiber, which was remarkably improved compared with $48 \mathrm{~dB} / \mathrm{m}$ of the unpurified $\mathrm{Ge}_{20} \mathrm{Sb}_{5} \mathrm{Se}_{75}$ fiber.
\end{abstract}

\section{Introduction}

Infrared (IR) transmitting optical fibers are receiving increasing attention because of their various applications, such as in radiometric thermometers, chemical analysis, thermal imaging, and infrared laser power delivery as in the case of $\mathrm{CO}_{2}$ lasers [1]. Materials and fabrication processes have been investigated to develop fibers. Our laboratory primarily focuses on IR-transmitting chalcogenide glasses (ChGs). The $\mathrm{Ge}-\mathrm{Sb}$-Se bulk glasses we produced have been used for military/civil infrared thermal imaging and have been provided to many domestic and foreign customers. These glasses are advantageous because of their broad IR transmitting windows (extending to $20 \mu \mathrm{m}$ ) and excellent thermal stability. Thus, we have been exploring IR fiber preparation using our Ge-Sb-Se glasses. However, the short-wavelength weak absorption tail (WAT) of these glasses is excessively high, which seriously enhances attenuation loss in the fibers. Given that the WAT normally comes from structural defects in the glass network [2], this tail is difficult to remove once the composition or glass structure has been decided. Hence, in our previous studies, we examined the $\mathrm{Ge}_{20} \mathrm{Sb}_{5} \mathrm{Se}_{75-\mathrm{x}} \mathrm{I}_{\mathrm{x}}(\mathrm{x}=0,5,10,15,20$ at\%) glass system and revealed the influence of halide iodine (I) on the optical properties of Ge-Sb-Se ChGs. Our study demonstrated that with the progressive substitution of I for Se from $\mathrm{x}=5$ to $\mathrm{x}=20$, the optical bandgap clearly increased and the WAT decreased significantly. The absorption coefficient $\alpha$ decreased from $2.741 \mathrm{~cm}^{-1}$ to 0.103 $\mathrm{cm}^{-1}$ in the short-wavelength region of $2.5 \mu \mathrm{m}$. We obtained the lowest absorption coefficient $\alpha$ of $0.029 \mathrm{~cm}^{-1}$ for the $\mathrm{Ge}_{20} \mathrm{Sb}_{5} \mathrm{Se}_{55} \mathrm{I}_{20}$ glass at the $10.16 \mu \mathrm{m}$ wavelength. The achieved maximum IR transparency of the new $\mathrm{Ge}-\mathrm{Sb}-\mathrm{Se}-\mathrm{I}$ glass system was near $80 \%$ with an effective transmission window between $0.94 \mu \mathrm{m}$ to $17 \mu \mathrm{m}$. A. P. 
Velmuzhov et al. also studied this glass system and they put forward a method for the preparation of these chalcoiodide glasses by reaction of iodides of p-elements with chalcogen melt. They prepared and investigated the Ge-Sb-Se-I system with low content of impurities and high infrared transparency [3]. Recently, we further investigated some physical natures of this Ge-Sb-Se-I glass system, and with Raman study, we revealed the structural evolution of this new glass system to further elucidate our early experimental results. Thus, we focused on studies of low-loss arsenic (As)-free IR fibers.

Numerous studies on the optical properties of ChGs [4,5] have indicated that hydrogen and oxygen impurity absorption, as well as the short-wavelength WAT, may be significant loss factors. Hydrogen impurity absorptions appear in the high-transparency wavelength region from $2 \mu \mathrm{m}$ to $5 \mu \mathrm{m}$. The WAT, which follows an exponential law, appears in the wavelength range of the Urbach tail. These absorptions are known to depend on the purity of the glass, so through a series of purification processes, we effectively decreased the absorption peaks caused by $\mathrm{Ge}-\mathrm{O}$, Se-H, and $\mathrm{H}_{2} \mathrm{O}$ to the greatest extent in the $\mathrm{Ge}_{20} \mathrm{Sb}_{5} \mathrm{Se}_{55} \mathrm{I}_{20}$ glass. Thus, we prepared $\mathrm{Ge}_{20} \mathrm{Sb}_{5} \mathrm{Se}_{75}$ and $\mathrm{Ge}_{20} \mathrm{Sb}_{5} \mathrm{Se}_{55} \mathrm{I}_{20}$ glass fibers using well-purified glasses. We also investigated some optical properties of these IR fibers to examine the possibility of ultralow-loss fiber in ChG systems without the element As.

\section{Glass preparation and characterization}

A series of $\mathrm{Ge}_{20} \mathrm{Sb}_{5} \mathrm{Se}_{75-\mathrm{x}} \mathrm{I}_{\mathrm{x}}(\mathrm{x}=0,5,10,15,20 \mathrm{at} \%)$ glass samples were prepared by the traditional

melt-quenching method and marked from G0 to G4. Elemental raw materials of high purity (i.e., Ge, 99.999\%; $\mathrm{Sb}, 99.999 \%$; Se, 99.999\%; and I, 99.99\%) with no further purification were carefully weighed and batched into

quartz ampoules, which were sealed under vacuum at a pressure of $2 \times 10^{-4} \mathrm{~Pa}$ using a gas-oxygen torch. The

quartz ampoules containing the raw materials were then heated slowly to $850{ }^{\circ} \mathrm{C}$ in rocking furnaces and maintained at this temperature for $20 \mathrm{~h}$ to ensure homogenization of the mixtures. Once homogenized, the melt-containing ampoules were quenched in water at room temperature and swiftly moved to a preheated furnace to anneal for $8 \mathrm{~h}$ to minimize the inner tension induced by the quenching step. The glass rods ( $9 \mathrm{~mm}$ in diameter and $100 \mathrm{~mm}$ in length) were removed from the ampoules and finally cut into discs of thicknesses $d$, as listed in Table 1. They were then polished to mirror smoothness on both sides for optical testing.

Table 1. Glass sample properties

\begin{tabular}{llllll}
\hline Sample & Composition & $\rho\left(\mathrm{g} \mathrm{cm}^{-3}\right)$ & $\mathrm{d}(\mathrm{cm})$ & $\mathrm{T}_{\mathrm{g}}\left({ }^{\circ} \mathrm{C}\right)$ & $\mathrm{T}_{\mathrm{p}}\left({ }^{\circ} \mathrm{C}\right)$ \\
\hline $\mathrm{G} 0$ & & & & \\
$\mathrm{G} 1$ & $\mathrm{Ge}_{20} \mathrm{Sb}_{5} \mathrm{Se}_{75}$ & 4.591 & 0.21 & 185.01 & 219.13 \\
$\mathrm{G} 2$ & $\mathrm{Ge}_{20} \mathrm{Sb}_{5} \mathrm{Se}_{70} \mathrm{I}_{5}$ & 4.396 & 0.20 & 171.03 & 201.19 \\
$\mathrm{G} 3$ & $\mathrm{Ge}_{20} \mathrm{Sb}_{5} \mathrm{Se}_{65} \mathrm{I}_{10}$ & 4.385 & 0.19 & 163.81 & 199.65 \\
$\mathrm{G} 4$ & $\mathrm{Ge}_{20} \mathrm{Sb}_{5} \mathrm{Se}_{60} \mathrm{I}_{15}$ & 4.376 & 0.21 & 147.25 & 189.15 \\
\hline & $\mathrm{Ge}_{20} \mathrm{Sb}_{5} \mathrm{Se}_{55} \mathrm{I}_{20}$ & 4.368 & 0.20 & 131.48 & 174.18 \\
\hline
\end{tabular}

Densities were measured according to the Archimedes principle using distilled water as immersion fluid with an accuracy of $0.001 \mathrm{~g} / \mathrm{cm}^{3}$. The amorphous nature of the glasses was determined by powder X-ray 
diffraction with a powder diffractometer (Bruker AXS GMBH) using $\mathrm{CuK}_{\alpha}$ radiation (36 kV, $\left.20 \mathrm{~mA}\right)$. The thermal parameters (i.e., $T_{g}$ and $T_{p}$ ) of these glasses were investigated with a thermal dilatometer (Netzsch DIL402) for the sample thickness of approximately $2 \mathrm{~mm}$. The parameters of $T_{\mathrm{g}}$ and $T_{\mathrm{p}}$ were tested using the thermal dilatometer (model: Netzsch DIL402) in our research. They were determined in the temperature range of $40{ }^{\circ} \mathrm{C}$ to $450{ }^{\circ} \mathrm{C}$ at a heating rate of $4{ }^{\circ} \mathrm{C} / \mathrm{min}$. The refractive indices of the samples were obtained using a prism coupling device (SAIRON SPA4000, South Korea). The Raman spectra of these glasses were measured at room temperature using the back $\left(180^{\circ}\right)$ scattering configuration of a laser confocal Raman spectrometer (Renishaw inVia, Gloucestershire, UK) with an Ar ion laser of $488 \mathrm{~nm}$ wavelength. A grating with 1800 groove/mm was used in these measurements. All optical tests were conducted at room temperature.

\section{Glass physical properties and discussions}

\subsection{XRD investigation}

Visual examination is impossible because the $\mathrm{ChG}$ glasses are black and totally opaque in the visible region (Fig. 1a). However, examination with a near-IR (NIR) imaging camera operating at the wavelength of $1 \mu \mathrm{m}$ indicates no evidence of crystal formation. Results show that fewer and smaller glass stripes appear in the glass, and the transparency is gradually improved with increasing I content (Fig. 1b). XRD analyses were conducted to further determine the amorphous state of each sample. The XRD patterns of the G0 to G4 glass samples are presented in Fig. 2. The XRD results showed that as the $2 \theta$ of the scanning range increases, the diffraction intensity experiences some fluctuations with the instrumental background line. No sharp peaks and crystalline phases are observed in the measured XRD spectra, so the amorphous nature of the synthesized glasses can be confirmed [6].
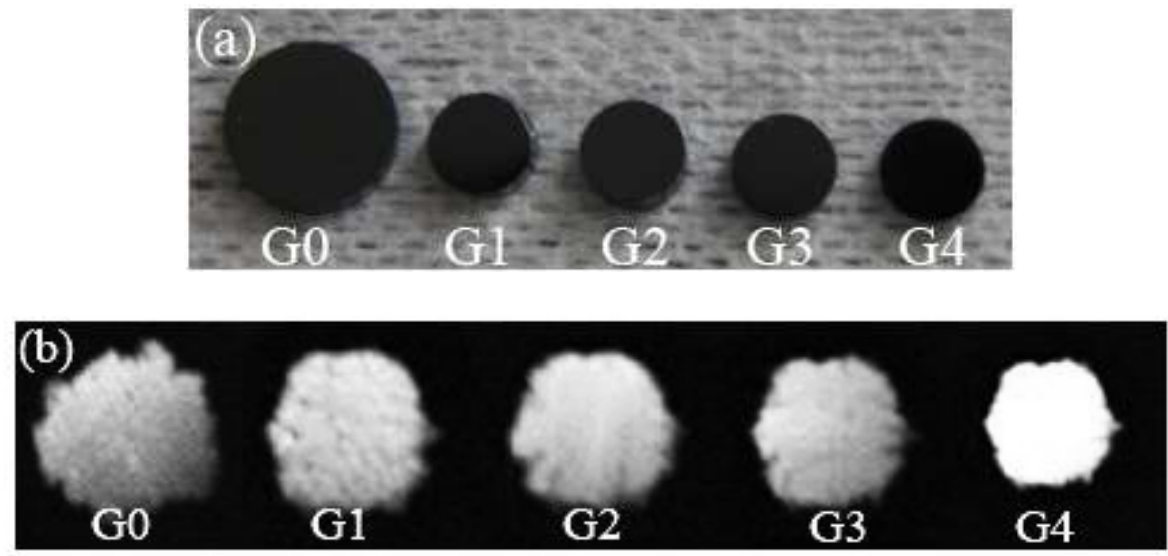

Fig. 1. (a) Visible region images and (b) images of stripes in different glasses taken with an NIR imaging camera operating at a wavelength

$$
\text { of } 1 \mu \mathrm{m}
$$

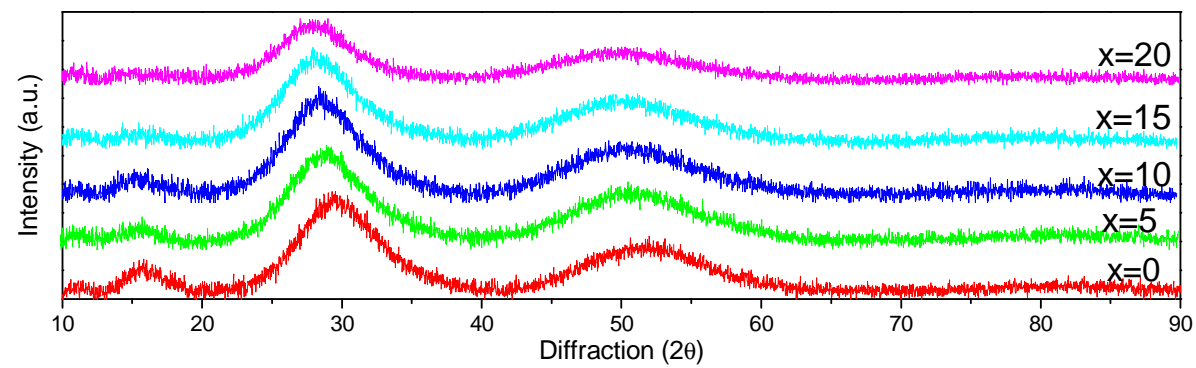

Fig. 2. XRD pattern of the $\mathrm{Ge}_{20} \mathrm{Sb}_{5} \mathrm{Se}_{75 \times} \mathrm{I}_{\mathrm{x}}$ glass samples 
The densities of the glass samples are shown in Fig. 3, and the results are listed in Table 1. The density, which is determined by the mean atom molar mass and packing efficiency of atoms, decreases rapidly from G0 to G4 [7,8]. As the I content increases, the packing efficiency of the atoms in the glass structure decreases and the average molar volume $\left(V_{m}\right)$ increases. Despite the larger atomic weight of I (127) than that of Se (79), the measured density $\rho$ decreases with the addition of I.

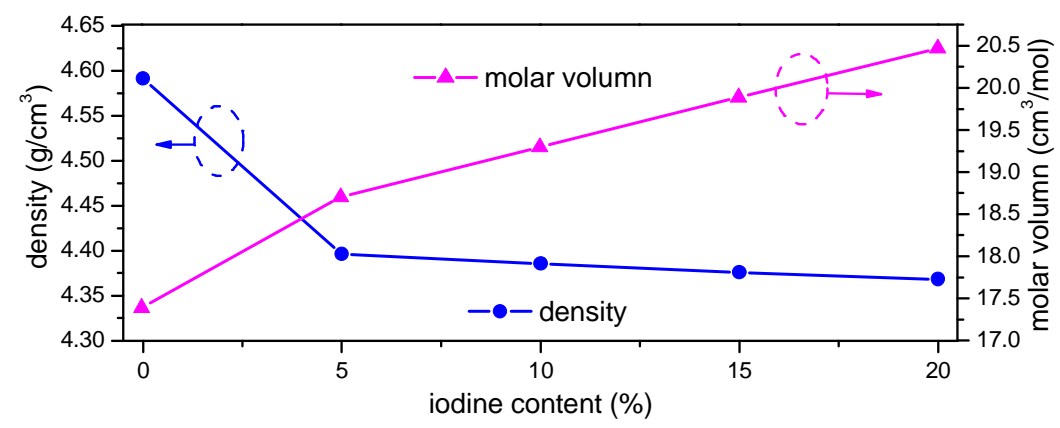

Fig. 3. Densities and molar volume of the $\mathrm{Ge}_{20} \mathrm{Sb}_{5} \mathrm{Se}_{75-\mathrm{x}} \mathrm{I}_{\mathrm{x}}$ glass samples

The thermal characteristics of the glass samples were investigated using a thermal dilatometer. Table 1 and Fig. 4 show that $T_{g}$ decreases with increasing I content. A minimum $T_{g}$ value of $131.48{ }^{\circ} \mathrm{C}$ is obtained for the $\mathrm{Ge}_{20} \mathrm{Sb}_{5} \mathrm{Se}_{55} \mathrm{I}_{20}$ glass.

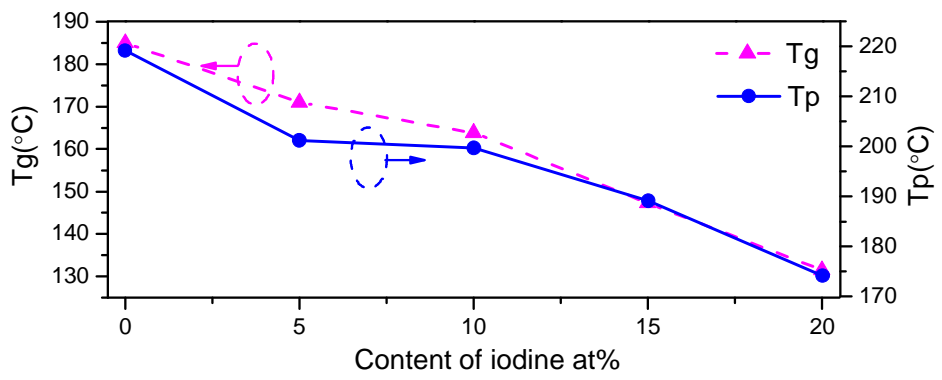

Fig. 4. Thermal parameters of the $\mathrm{Ge}_{20} \mathrm{Sb}_{5} \mathrm{Se}_{75-\mathrm{x}} \mathrm{I}_{\mathrm{x}}$ glass samples

The decrease in the glass transition temperature $T_{g}$ can be attributed to the difference in the average bond energies of the glasses. The energies of different possible bonds listed in Table 2 can be calculated on the basis of the relation postulated by Pauling.

$$
D(a-b)=[D(a-a) * D(b-b)]^{0.5}+30\left(\chi_{a}-\chi_{b}\right)^{2}
$$

where $\chi_{a}$ and $\chi_{b}$ are the electronegativity values of atoms $a$ and $b$, and $D(a-a)$ and $D(b-b)$ are the bond energies of the $a-a$ and $b-b$ bonds, respectively.

The bonds are formed in the sequence of decreasing bond energies until all available valences for the atoms are saturated $[9,10]$. The drop in the $T_{g}$ and $T_{p}$ in this Ge-Sb-Se-I glass system is due to the formation of the weaker Ge-I and Se-I bonds, as well as the reduction in the stronger Ge-Se, Se-Se, and Sb-Se bonds (which is confirmed by a succeeding Raman investigation) with the addition of I to the $\mathrm{Ge}-\mathrm{Sb}-\mathrm{Se}$ glasses. The smaller the average bond energy, the lower the glass transition temperature of an amorphous glass system becomes.

Table 2. Bond energy values of different possible bonds

\begin{tabular}{ll}
\hline Bonds & Bond energy $(\mathrm{kJ} / \mathrm{mol})$ \\
\hline Ge-Se & 205.607 \\
\hline
\end{tabular}




\begin{tabular}{ll}
\hline Ge-I & 186.971 \\
Se-Se & 184.096 \\
Sb-Se & 183.845 \\
Se-I & 167.929 \\
Ge-Ge & 154.808 \\
I-I & 151.001 \\
Sb-I & 145.675 \\
Ge-Sb & 141.168 \\
Sb-Sb & 126.440 \\
\hline
\end{tabular}

The $T_{p}$ values (the thermal expansion coefficient reaches the peak value at this temperature) of these glasses are near $200{ }^{\circ} \mathrm{C}$, which are close to the heat deflection temperature of polyethersulfone (PES) at $203{ }^{\circ} \mathrm{C}$, thereby making fiber coating with polymer PES possible.

\subsection{Optical absorption and transmission spectra}

The measured Vis-NIR absorption spectra of the glass samples are shown in Fig. 5. In the short-wavelength region, each loss consists of two exponential parts. The steep sloping line corresponds to the Urbach tail and the gradual sloping line to the WAT. The WAT dominates the loss factors in chalcogenide glass fibers [11]. Before the addition of I, the absorption coefficient of $\mathrm{Ge}_{20} \mathrm{Sb}_{5} \mathrm{Se}_{75}$ glass is excessively high in the WAT region (Fig. 5). However, the WAT amplitude of the $\mathrm{Ge}_{20} \mathrm{Sb}_{5} \mathrm{Se}_{75-x} \mathrm{I}_{\mathrm{x}}$ glass has considerably decreased with the gradual substitution of I for Se from $\mathrm{x}=5$ to $\mathrm{x}=20$.

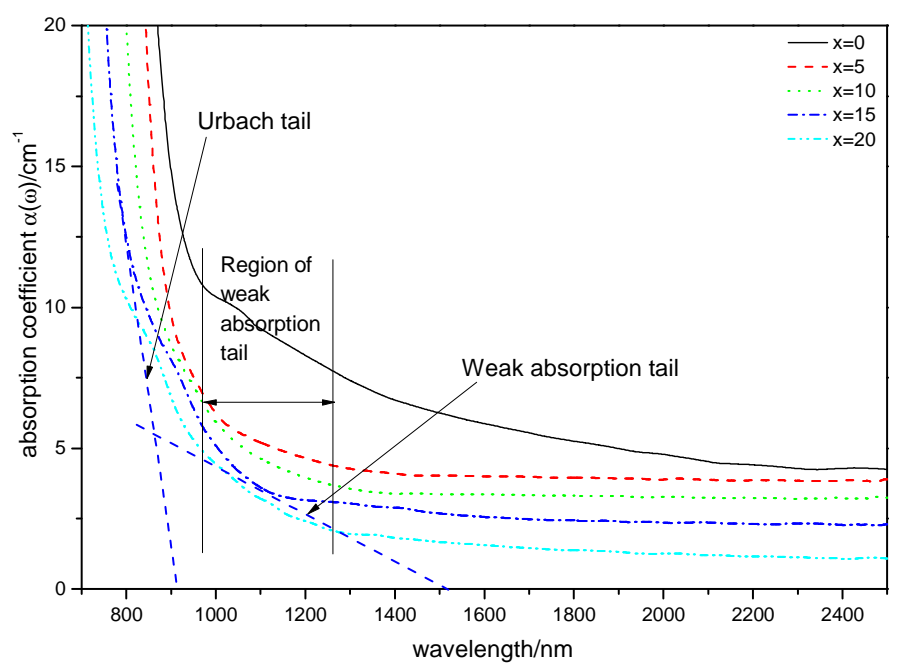

Fig. 5. Absorption spectra of the $\mathrm{Ge}_{20} \mathrm{Sb}_{5} \mathrm{Se}_{75-\mathrm{x}} \mathrm{I}_{\mathrm{x}}$ glass samples.

The transparency of the $\mathrm{Ge}-\mathrm{Sb}-\mathrm{Se}-\mathrm{I}$ glass system extends from the band gap region at $0.94 \mu \mathrm{m}$ to the phonon region at approximately $17 \mu \mathrm{m}$ as shown in Fig. 6. The addition of I has positive effects on improving the transparency of this glass system. The transmittance of IR light increased remarkably with the increasing I content. The maximum average transmission percentage in the mid-IR region can reach up to almost $80 \%$ with 20 at $\%$ of I content. The increased transparency can be explained by the following two factors. On the one hand, 
the relatively smaller polarization of halogen I will impel the glass refractive index to decrease with the increasing I content, which brings less Fresnel's reflective losses. On the other hand, unlike the original $\mathrm{Ge}-\mathrm{Sb}-\mathrm{Se}$ glass system, the less glass net-work defects and gradually enhanced glass-forming ability lead to a decreased scattering loss in the ameliorative glass system.

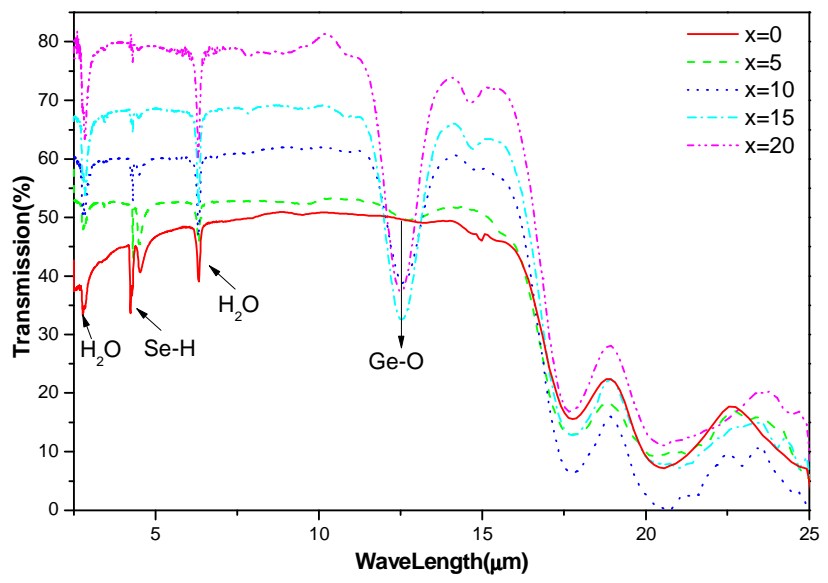

Fig. 6. IR transmission spectra of the glass sample.

\subsection{Raman peak fitting and analysis}

We adopted the Raman spectra of the glasses to reveal the structural evolutions in this glass system and further understand the experimental results in our early reports. The fitted spectra presented in this section were background corrected and normalized to the maximum intensity of the broad band to determine the variation in the structural units and influence of vibrational modes of each unit on the overall Raman spectrum. The compositional dependence of the Raman spectra of the $\mathrm{Ge}_{20} \mathrm{Sb}_{5} \mathrm{Se}_{75-\mathrm{x}} \mathrm{I}_{\mathrm{x}}$ glasses is presented in Fig. 7 and dominated by several overlapping bands between $100 \mathrm{~cm}^{-1}$ and $400 \mathrm{~cm}^{-1}$.

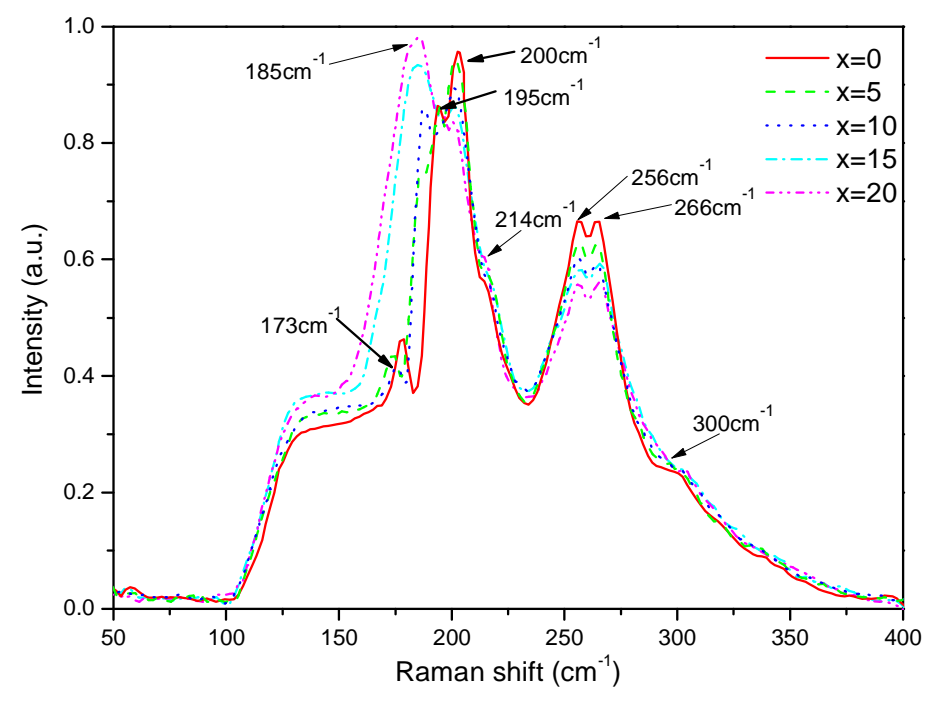

Fig. 7. Normalized Raman spectra of the $\mathrm{Ge}_{20} \mathrm{Sb}_{5} \mathrm{Se}_{75-\mathrm{x}} \mathrm{I}_{\mathrm{x}}$ glasses

The general features that dominate the Raman spectrum of the glass can be summarized as follows:

(1) The most intense Raman band at $200 \mathrm{~cm}^{-1}$ and its shoulder called "companion peak" at $214 \mathrm{~cm}^{-1}$ are attributed to the symmetrical stretching vibration of $\mathrm{Ge}-\mathrm{Se}$ bonds in the corner-sharing $\mathrm{GeSe}_{4 / 2}$ tetrahedra and edge-sharing $\mathrm{Ge}_{2} \mathrm{Se}_{8 / 2}$ bi-tetrahedra, respectively [12,13]. 
(2) The broad, low-intensity Raman bands at 256 and $266 \mathrm{~cm}^{-1}$ with a shoulder at $300 \mathrm{~cm}^{-1}$ are due to the vibration of the $\mathrm{Se}_{\mathrm{n}}$ rings and $\mathrm{Se}-\mathrm{Se}$ chains, respectively $[12,13]$.

(3) The shoulder at $173 \mathrm{~cm}^{-1}$ is associated with the vibrations of related $\mathrm{Ge}-\mathrm{Se}$ bonds in the $\mathrm{Se}_{3} \mathrm{Ge}-\mathrm{GeSe}_{3}$ units [14].

(4) The peak at $195 \mathrm{~cm}^{-1}$ can be ascribed to the vibration of the heteropolar $\mathrm{Sb}-\mathrm{Se}$ bonds in $\mathrm{SbSe}_{3 / 2}$ pyramids connected through a bridging Se [15]. However, the peak is unclear in the Raman spectra because of its overlapping with the Ge-Se vibrational bands and low Sb concentration in the investigated glasses.

(5) The absence of the band at $150 \mathrm{~cm}^{-1}$ indicates the absence of $\mathrm{Sb}-\mathrm{Sb}$ bonds in the $\mathrm{Se}_{2} \mathrm{Sb}-\mathrm{SbSe}_{2}$ structural units [16], which is consistent with the very low Sb concentration in the investigated glasses.

The changes in the Raman spectra with I incorporation exhibited the following characteristics:

(1) The amplitudes of the 200 and $174 \mathrm{~cm}^{-1}$ bands are reduced, which shows the decrease in corner-shared $\left(\mathrm{GeSe}_{4}\right)$ tetrahedral and $\mathrm{Se}_{3} \mathrm{Ge}-\mathrm{GeSe}_{3}$ units in I-incorporated glasses. The band at $174 \mathrm{~cm}^{-1}$ clearly disappears in the glasses with I concentration of more than $10 \%$. Given that the bond energy of Ge-I is larger than that of $\mathrm{Ge}-\mathrm{Ge}, \mathrm{Ge}$ is preferentially bonded with I and would lead to the formation of Ge-I bonds with the addition of I. Part of the Se atoms in the $\mathrm{GeSe}_{4}$ units are replaced by I atoms in the newly formed glass system. Additionally, I can break the $\left(\mathrm{Se}_{3} \mathrm{Ge}-\mathrm{GeSe}_{3}\right)$ units to form complex $\mathrm{GeSe}_{4-\mathrm{x}} \mathrm{I}_{\mathrm{x}}$ units, especially under a large amount of I. Thus, the intensity of these bands decreases gradually. When the concentration of I increases to $15 \%$, a significant new band emerges at $185 \mathrm{~cm}^{-1}$ and enlarges quickly because of the Ge-I vibration.

(2) The bands located at $214 \mathrm{~cm}^{-1}$ do not significantly vary until $x$ increases up to 20 . This scenario indicates that the incorporation of $\mathrm{I}$ in the glass network mainly breaks the connection of the corner-sharing $\mathrm{GeSe}_{4 / 2}$ tetrahedra units rather than the two edge-sharing $\mathrm{Ge}_{2} \mathrm{Se}_{8 / 2}$ bi-tetrahedra because of the firmer bonding of edge-sharing than corner-sharing.

(3) The other remarkable feature extracted from the peak fitting curve is the evolution of the ratio of the total defective Se-Se bonds to that of the whole Raman spectra, as shown in Figure 7. The amplitude corresponding to the homopolar Se-Se bonds in the Se chains and rings remarkably decreases with the progressive introduction of I. This phenomenon demonstrates the decrease in relative ratio of the homopolar Se-Se bonds.

All these results can be connected with the variation in the attenuation loss and optical bandgap shown in our previous studies. The existence of defective units in the amorphous materials forms band-tails below the conduction band or above the valence band, and the presence of more defects broadens the energy level of the band-tails and narrows the optical bandgap [17,18]_ENREF_25. The formation of new $\mathrm{GeSe}_{4-\mathrm{x}} \mathrm{I}_{\mathrm{x}}$ units indicates that the dangling bonds in the Se chains, Se rings, and $\mathrm{GeSe}_{3}$ units have gradually been repaired. Thus, the absorption coefficient in the WAT of this I-modified glass system decreases effectively.

\section{Fabrication of fibers}

\subsection{Glass purification and fiber drawing}

For the $\mathrm{Ge}_{20} \mathrm{Sb}_{5} \mathrm{Se}_{75-\mathrm{x}} \mathrm{I}_{\mathrm{x}}(\mathrm{x}=0,5,10,15,20$ at \%) glass system, the amplitude of the weak absorption tail decreases and the transparency in the IR region increases with the gradually introducing of iodine. Actually, when the iodine content exceeds $20 \%$, the glass begins to crystalize gradually and the IR transparency decreases sharply. So $20 \%$ iodine doping content is the critical value above which the glasses are unsuitable for fabricating low-loss IR fibers. So we finally select $\mathrm{Ge}_{20} \mathrm{Sb}_{5} \mathrm{Se}_{55} \mathrm{I}_{20}$ as the optimum glass composition for glass fiber preparation.

The raw materials of Ge-Sb-Se-I glass were pretreated to reduce impurities such as hydrogen and oxygen. $\mathrm{Ge}, \mathrm{Sb}$, and Se were treated with acid to clean the surface, and I was purified by vacuum sublimation. Then, all the pretreated materials doped with a small amount of magnesium $(\mathrm{Mg})$ powder as an oxygen getter were introduced into an evaporator (Fig. 8). The whole setup was then sealed in a vacuum at $2 \times 10^{-3} \mathrm{~Pa}$. In an 
appropriate two-heating zone furnace, the temperature of the evaporator was progressively increased to $950{ }^{\circ} \mathrm{C}$, and the receiver was kept at a low temperature. All starting elements were then distilled into the receiver apart from the oxide impurities (e.g., $\mathrm{MgO}$ ). The receiver was then sealed and put into a rocking furnace for melting. A glass rod of $9 \mathrm{~mm}$ diameter and $100 \mathrm{~mm}$ length was then obtained.

Fig. 9 shows the optical transmission of $\mathrm{Ge}_{20} \mathrm{Sb}_{5} \mathrm{Se}_{55} \mathrm{I}_{20}$ glass with and without purification. The broad absorption in the $11 \mu \mathrm{m}-13 \mu \mathrm{m}$ regions is due to oxygen impurity. This peak is considerably weakened after $\mathrm{Mg}$ reacted with the oxygen in the raw materials. In the purified curve 1, the absorption peaks caused by $\mathrm{H}_{2} \mathrm{O}$ around 2.8 and $6.3 \mu \mathrm{m}$ become very weak, and the peak located at $4.3 \mu \mathrm{m}$ caused by the Se-H vibration almost disappears through the vacuum sublimation to I.

The purified $\mathrm{Ge}_{20} \mathrm{Sb}_{5} \mathrm{Se}_{55} \mathrm{I}_{20}$ glass rod was zonally heated to $330{ }^{\circ} \mathrm{C}$ in an electric furnace with a quartz cylindrical muffle and then drawn into fibers under $\mathrm{N}_{2}$ gas flow in our homemade drawing tower. The drawn fibers were $300 \mu \mathrm{m}$ in diameter and $50 \mathrm{~m}$ in length.

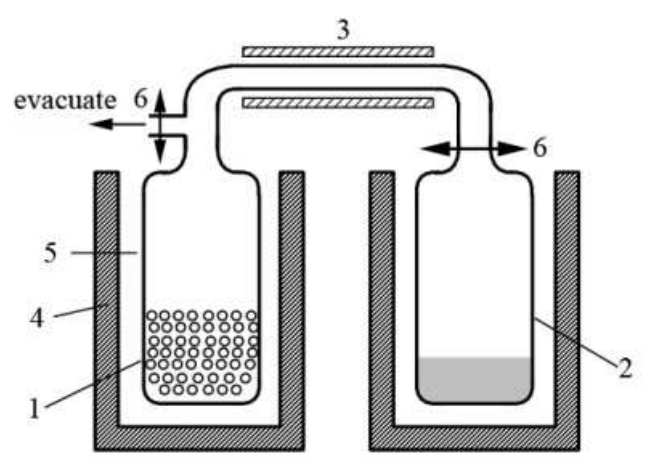

Fig. 8. The setup for glass preparation:

(1) evaporator, (2) receiver, (3) heated tube, (4) temperature-controlled furnace, (5) thermal coupling material, and (6) sealing position

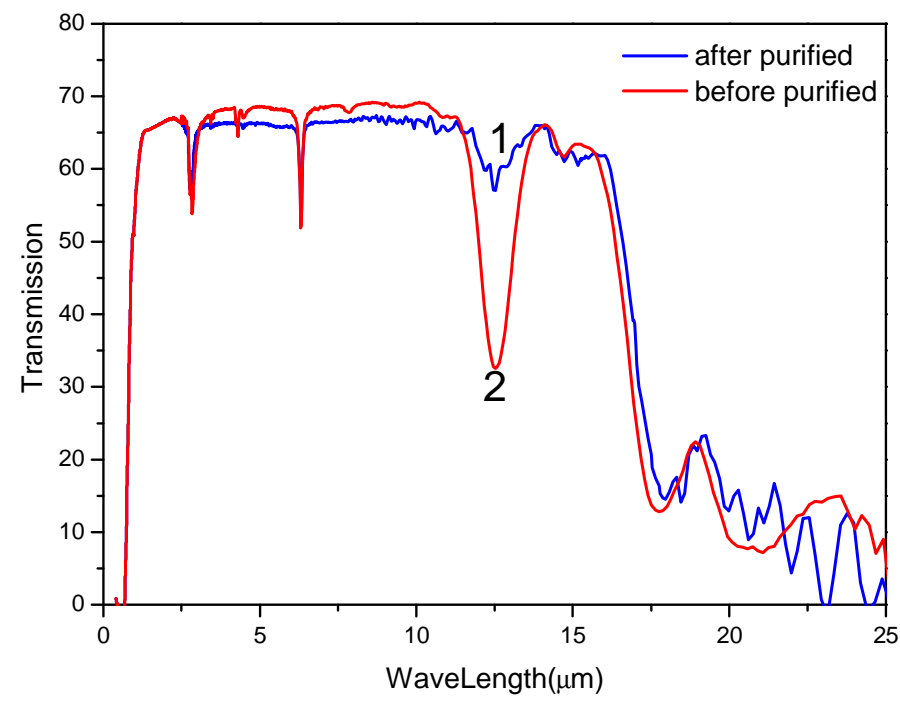

Fig. 9. Optical transmission spectra of $\mathrm{Ge}_{20} \mathrm{Sb}_{5} \mathrm{Se}_{55} \mathrm{I}_{20}$ glasses (2 mm thick) (1) glass purified with Mg getter and (2) glass without purification

\subsection{Measurement and discussion}

\subsubsection{Fiber transmission loss}

The fiber transmission loss was measured using the standard cutback method with a Nicolet 5700 FTIR instrument. The length of the fibers with both facets polished varied from $10 \mathrm{~cm}$ to $100 \mathrm{~cm}$. The fiber ends were formed by the knife-cutting method. Figure 10(a) shows an image of the fiber end surface obtained using a digital microscope. A globar source and a liquid nitrogen-cooled area MCT detector were used in the $2.5 \mu \mathrm{m}-15 \mu \mathrm{m}$ region. The FTIR light beam was first collimated 
using a gold-plated parabola reflector and then focused into the core of the fiber under test with an aspheric lens ( $\mathrm{ZnSe}$ lens, $\mathrm{f}$ $=5 \mathrm{~mm}$ ). Finally, the transmitted light was measured by the MCT detector abutted to the fiber output facet.

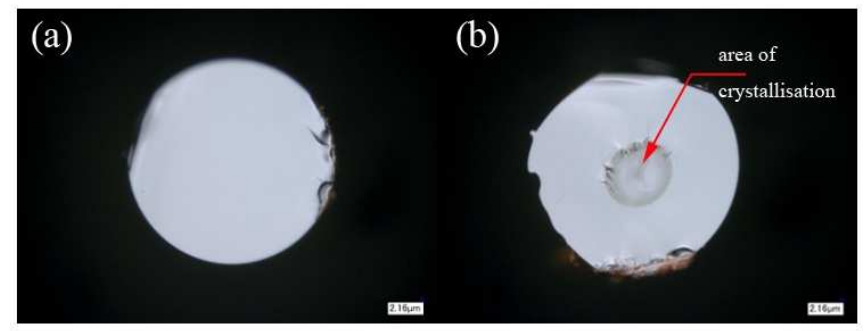

Fig. 10. Drawn fiber end under the digital microscope:

(a) perfect fiber end without crystallization and (b) fiber end surface with local crystallization

The transmission loss spectra of $\mathrm{Ge}_{20} \mathrm{Sb}_{5} \mathrm{Se}_{75}$ fiber $300 \mu \mathrm{m}$ in diameter is shown in Fig. 11(a). The absorption peaks are caused by hydrogen and oxygen impurities. The peak at $4.3 \mu \mathrm{m}$ arises from the Se-H fundamental stretching vibration [5]. The peak caused by $\mathrm{H}_{2} \mathrm{O}$ is located at $6.31 \mu \mathrm{m}$. The large peak at $11.9 \mu \mathrm{m}$ is attributed to oxide impurities [5]. The lowest loss is $49 \mathrm{~dB} / \mathrm{m}$.

Fig. 11(b) shows the transmission loss spectra of the $\mathrm{Ge}_{20} \mathrm{Sb}_{5} \mathrm{Se}_{55} \mathrm{I}_{20}$ fiber with a diameter of $300 \mu \mathrm{m}$. The absorption peak at around 2.7 and $3.0 \mu \mathrm{m}$ are caused by the $\mathrm{O}-\mathrm{H}$ fundamental stretching vibration. The absorption band at $3.2 \mu \mathrm{m}$ is due to carbon impurity [4]. The large peak at $4.5 \mu \mathrm{m}$ is due to the Se-H fundamental stretching vibration, whereas those around 6.3 and $9.3 \mu \mathrm{m}$ are due to molecular $\mathrm{H}_{2} \mathrm{O}$ and oxide impurity, respectively [19]. The peak at around $10.3 \mu \mathrm{m}$ corresponds to Se-Se bond vibration (four-phonon process) and oxide impurity absorption [5,20]. These impurity absorption peaks originate mainly from the extremely small amount of the residual oxygen and $\mathrm{H}_{2} \mathrm{O}$, which had not been removed from the raw materials.

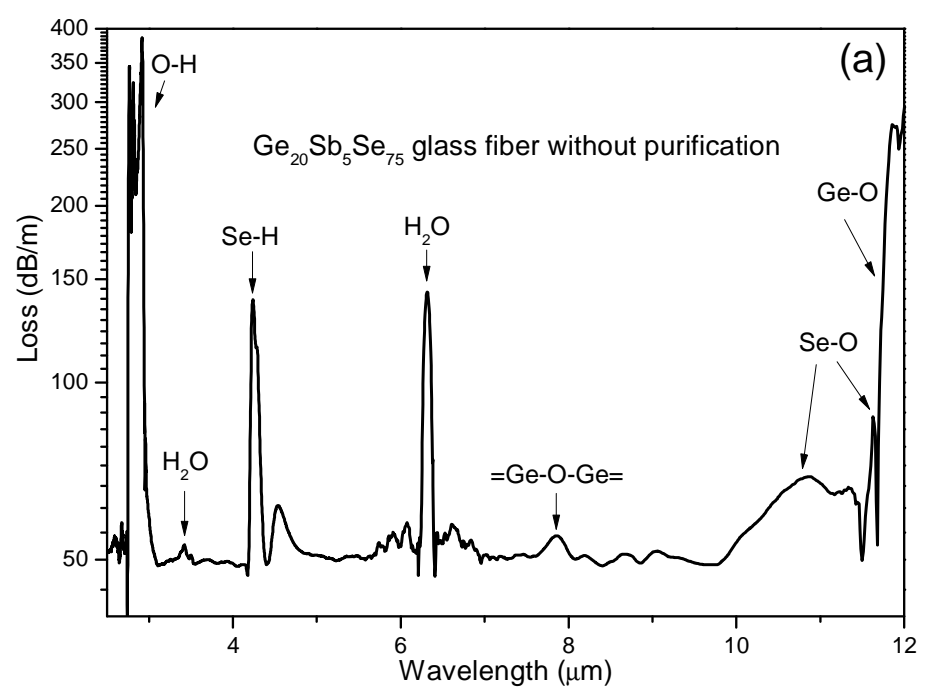




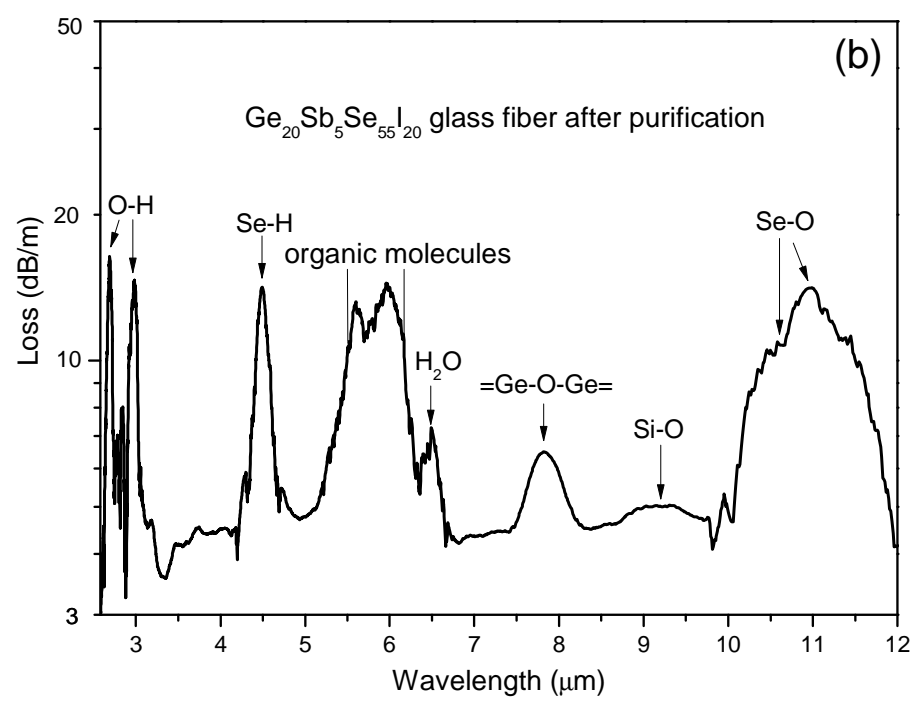

Fig. 11. Transmitting loss spectra of (a) $\mathrm{Ge}_{20} \mathrm{Sb}_{5} \mathrm{Se}_{75}$ and (b) $\mathrm{Ge}_{25} \mathrm{Sb}_{5} \mathrm{Se}_{55} \mathrm{I}_{20}$ fibers

In general, the loss curve character of $\mathrm{Ge}_{20} \mathrm{Sb}_{5} \mathrm{Se}_{55} \mathrm{I}_{20}$ fiber is similar to that of the $\mathrm{Ge}_{20} \mathrm{Sb}_{5} \mathrm{Se}_{75}$ fiber, but with much lower average transmission loss. The lowest loss $(3.55 \mathrm{~dB} / \mathrm{m})$ is obtained at $3.3 \mu \mathrm{m}$ for the $\mathrm{Ge}_{20} \mathrm{Sb}_{5} \mathrm{Se}_{55} \mathrm{I}_{20}$ glass fiber, and minimum losses are $4.7,4.33$, and $4.5 \mathrm{~dB} / \mathrm{m}$ at 5, 7, and $8.4 \mu \mathrm{m}$, respectively. The $\mathrm{Ge}_{20} \mathrm{Sb}_{5} \mathrm{Se}_{75} \mathrm{I}_{20}$ glass has much less structural defects after glass network optimization, and most impurities are eliminated through distillation and sublimation purification processes. Thus, this fiber exhibits much lower loss. As we had previously confirmed, the WAT amplitude of the $\mathrm{Ge}_{20} \mathrm{Sb}_{5} \mathrm{Se}_{75-\mathrm{x}} \mathrm{I}_{\mathrm{x}}$ bulk glass considerably decreases with the gradual substitution of I for Se from $\mathrm{x}=5$ to $\mathrm{x}=20$, and WAT dominates the loss factors in ChG glass fibers. Accordingly, the relative amplitude of the loss for the $I_{20}$ fiber is the lowest in the short-wavelength region, as shown in the $3 \mu \mathrm{m}-4 \mu \mathrm{m}$ region.

Unlike the transmitting loss spectra of $\mathrm{Ge}_{20} \mathrm{Sb}_{5} \mathrm{Se}_{75}$ glass fiber, a relatively higher and wider absorbing peak caused by organic molecules absorption located between 5.5-6.2 $\mu \mathrm{m}$ was observed [21]. In the process of our fiber transmission loss test, we need to clean the fiber ends with organic cleaning solution. However, $\mathrm{Ge}_{25} \mathrm{Sb}_{5} \mathrm{Se}_{55} \mathrm{I}_{20}$ fiber contains iodine which is nonpolar and very easily combined with organic solution. So this organic molecules related absorption peak was brought during our testing process.

Introducing I to $\mathrm{Ge}_{20} \mathrm{Sb}_{5} \mathrm{Se}_{75}$ also affects the long-wavelength multiphonon region. With the addition of I to replace $\mathrm{Se}$ in the Ge-Sb-Se-I glass system, the multiphonon absorption peaks slightly shift to longer wavelength, and the absorption intensities are decreased (Fig. 11). The absorption peak at about $12 \mu \mathrm{m}$ caused by Ge-Se bonds is reduced for $\mathrm{I}_{20}$ fiber. Thus, the transparency region slightly expands toward longer wavelengths (from $10 \mu \mathrm{m}$ to $11 \mu \mathrm{m}$ ). The introduction of I atoms is accompanied by the formation of bonds, such as Ge-I, for which absorptions caused by vibration might occur at longer wavelength than those of Ge-Se bonds. This vibration results from the small increase in the reduced mass by the addition of I (slightly heavier than Se atom) in accordance to the following relation:

$$
\lambda \propto \sqrt{\frac{\mu}{k}}
$$

where $\lambda$ is the wavelength at which absorption occurs due to the vibration, $\mu$ is the reduced mass $[\mu=M 1 * M 2 /(M 1+M 2)$, in which $\mathrm{M} 1$ and $\mathrm{M} 2$ are the atomic masses of the participating (bond forming) atoms], and $k$ is the force constant that depends on the nature and strength of the bond. When the atomic mass increases because of the incorporation of I, the absorption wavelength increases, which is the dominant factor.

The other reason for the increase in atomic mass is due to the fact that in the melt at the reaction 
temperature and the relative ratio between the elements, the contamination of $\mathrm{Ge}-\mathrm{O}$ peak had been replaced by another oxide $(\mathrm{MgO})$ based on the thermodynamic stability of the oxides at $950{ }^{\circ} \mathrm{C}$ : $\mathrm{Mg}-\mathrm{O}>\mathrm{Ge}-\mathrm{O}>\mathrm{Se}-\mathrm{O}>\mathrm{Sb}-\mathrm{O}$ [22]. $\mathrm{MgO}$ has absorption peaks located far away after $12.5 \mu \mathrm{m}$.

The obtained value attenuation of the $\mathrm{Ge}_{20} \mathrm{Sb}_{5} \mathrm{Se}_{75} \mathrm{I}_{20}$ fiber remains much higher than desired, although it is much lower compared with that of the Ge-Sb-Se fiber. The glass rod was probably heated too close to $T_{x}$ and crystals formed, which contributed to light scattering. The index number $(n)$, which exhibits the wavelength dependence of the transmission loss, was estimated according to the equation (transmission loss) $\propto$ (wavelength) $^{-\mathrm{n}}$ to clarify the effect of light scattering. The index numbers are 4.368 and 4.591 for the $\mathrm{Ge}_{20} \mathrm{Sb}_{5} \mathrm{Se}_{55} \mathrm{I}_{20}$ and $\mathrm{Ge}_{20} \mathrm{Sb}_{5} \mathrm{Se}_{75}$ glasses, respectively. This result indicates that Rayleigh scattering is dominant in the scattering loss for the I-rich glass fiber, and this characteristic may be enhanced further by microcrystallization during the fiber drawing process. This phenomenon is due to the insufficient sensitivity of our temperature control device in the fiber drawing system to avoid crystallization. The same effect of unstable glasses during fiber drawing was also observed by the addition of $\mathrm{Te}$ to the $\mathrm{As}_{2} \mathrm{Se}_{3}$ system [23]. A micrograph of a partially crystallized fiber cross-section caused by extremely high drawing temperature is shown in Fig. 10(b). Sublimation of $\mathrm{I}$, which caused surface irregularity, is also observed in the prepared $\mathrm{I}_{20}$ fibers. All these nonhomogeneities increased the transmission loss of the drawn fiber.

\subsubsection{Fiber bending loss}

The bending loss of $\mathrm{Ge}_{25} \mathrm{Sb}_{5} \mathrm{Se}_{55} \mathrm{I}_{20}$ fiber was calculated using the following equation:

$$
\operatorname{Loss}_{\text {bend }}=-10 \log \left(\frac{T_{\text {bend }}}{T_{0}}\right)
$$

where $T_{0}$ is the transmittance of the straight fiber. The bend angle dependence of the loss for this glass fiber in the angle range from $0^{\circ}$ to $130^{\circ}$ is shown in Fig. 12 . When the bending angle is increased from $45^{\circ}$ to $135^{\circ}$, the introduced additional loss by bending fiber changes noticeably from $1.4 \mathrm{~dB}$ to $4.1 \mathrm{~dB}$. This result shows that the light transmission of the fiber is not very insensitive to bending angles, and an appropriate cladding is necessary for the actual applications to limit the light transmission only in the core of the fiber.

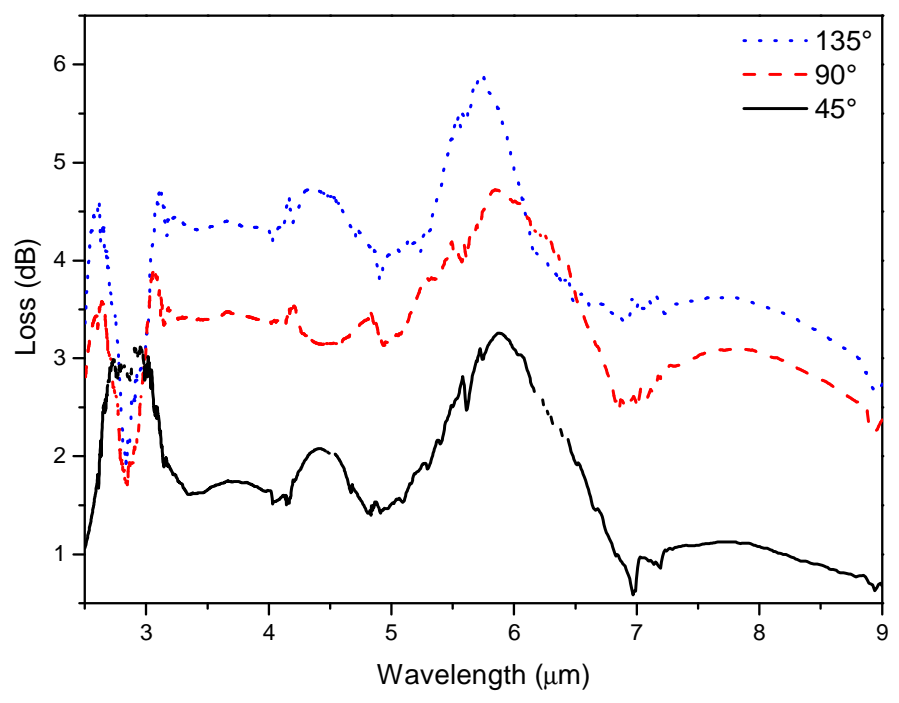

Fig. 12. Bend loss spectra of the $\mathrm{Ge}_{20} \mathrm{Sb}_{5} \mathrm{Se}_{55} \mathrm{I}_{20}$ optical fiber

\subsubsection{The test of laser power-induced damage threshold}

The experiments on $\mathrm{CO}_{2}$ laser power-induced damage threshold were performed with the $\mathrm{Ge}_{20} \mathrm{Sb}_{5} \mathrm{Se}_{55} \mathrm{I}_{20}$ 
glass fiber. The fiber length and the diameter were $1 \mathrm{~m}$ and $300 \mu \mathrm{m}$, respectively. This fiber is fused at the input laser power of $0.92 \mathrm{~W}$, and fiber gasification occurs when laser power reached $1.4 \mathrm{~W}$. At the wavelength of $\mathrm{CO}_{2}$ laser $(10.6 \mu \mathrm{m})$ the fiber loss is $10.32 \mathrm{~dB} / \mathrm{m}$. Thus, the thermal damage to the fiber is caused by the low glass transition temperature and the relatively high absorption at $10.6 \mu \mathrm{m}$ compared with the As-contained fibers.

\section{Conclusion}

We investigated some physical and optical properties of the Ge-Sb-Se-I glass system. Then, we purified the $\mathrm{Ge}_{20} \mathrm{Sb}_{5} \mathrm{Se}_{55} \mathrm{I}_{20}$ glass through vacuum distillation and sublimation to reduce impurities such as hydrogen and oxygen. $\mathrm{A} \mathrm{Ge}_{20} \mathrm{Sb}_{5} \mathrm{Se}_{55} \mathrm{I}_{20}$ glass fiber of $300 \mu \mathrm{m}$ in diameter and $50 \mathrm{~m}$ in length was fabricated for testing. The transmission loss of I-doped $\mathrm{Ge}_{20} \mathrm{Sb}_{5} \mathrm{Se}_{55} \mathrm{I}_{20}$ fiber greatly decreased compared with that of the $\mathrm{Ge}_{20} \mathrm{Sb}_{5} \mathrm{Se}_{75}$ fiber. The lowest loss $(3.55 \mathrm{~dB} / \mathrm{m})$ was achieved at $3.3 \mu \mathrm{m}$. This ChG glass fiber will be applicable to short fiber-length transmission media because of its wide operating wavelength range of $1 \mu \mathrm{m}-11 \mu \mathrm{m}$. The WAT of the fiber was effectively reduced in the short-wavelength region, and the absorption in the long-wavelength region caused by oxygen impurities was also decreased by our purification process. The $\mathrm{CO}_{2}$ laser power-induced damage threshold was $0.92 \mathrm{~W}$, which originated from the low glass $T g$ of $131.48^{\circ} \mathrm{C}$ and the larger absorption compared with the As-contained IR fibers.

\section{Acknowledgments}

This work was financially supported by the Natural Science Foundation of China (Grant Nos. 61435009, 61377099, and 61177087), the National Program on Key Basic Research Project (973 Program) (Grant No. 2012CB722703), the International Science \& Technology Cooperation Program of China (Grant No. 2011DFA12040), the Scientific Research Fund of Zhejiang Provincial Education Department (R1101263), the Natural Science Foundation of Ningbo (Grant No. 2013A610118), the Teaching and Research Award Program for Outstanding Young Teachers in Higher Education Institutions of MOE, P.R.C. Ningbo Optoelectronic Materials and Devices Creative Team (2009B21007), the Scientific Research Foundation of the Graduate School of Ningbo University, and the K. C. Wong Magna Fund of Ningbo University.

\section{References}

1. I. Inagawa, T. Yamagishi, T. Yamashita, Jpn. J. Appl. Phys. 30, 2846 (1991)

2. D. Wood, J. Tauc, Phys. Rev. B 5, 3144 (1972)

3. A. P. Velmuzhov, A. A. Sibirkin, V. S. Shiryaev, M. F. Churbanov, A. I. Suchkov, A. M. Potapov, M. V. Sukhanov, V. G. Plotnichenko, V. V. Koltashev, A. D. Plekhovich, J. Non-Cryst. Solids. 405, 100(2014)

4. J. Savage, S. Nielsen, Infrared Phys. Techn. 5, 195 (1965)

5. C. Moynihan, P. Macedo, M. Maklad, R. Mohr, R. Howard, J. Non-Cryst. Solids 17, 369 (1975).

6. S. Danto, P. Houizot, C. Boussard-Pledel, X. H. Zhang, F. Smektala, J. Lucas, Adv. Funct. Mater. 16, 1847 (2006)

7. H. Wang, G. Yang, Y. Xu, X. Zhang, Z. Gu, G. Chen, J. Chin. Ceram. Soc. 35, 922 (2007)

8. S. M. El-sayed, H. M. Saad, G. A. Amin, F. M. Hafez, M. Abd-El-Rahman, J. Phys. Chem. Solids 68, 1040 (2007)

9. A. S. Soltan, M. Abu El-Oyoun, A. A. Abu-Sehly, A. Y. Abdel-Latief, Mater. Chem. Phys. 82, 101 (2003).

10. V. Sadagopan, H. C. Gatos, Solid State Electron. 8, 529 (1965)

11. T. Kanamori, Y. Terunuma, S. Takahashi, T. Miyashita, J. Lightwave Technol. 2, 607 (1984)

12. S. El-Sayed, Semicond. Sci. Tech. 18, 337 (2003)

13. D. Goyal, A. Maan, J. Non-Cryst. Solids 183, 182 (1995)

14. W. Chen, J. Am. Ceram. Soc. 91, 1686 (2008) 
15. J. Holubova, Z. Černošek, E. Černošková, Optoelectron. Adv. Mat. 1, 663 (2007)

16. Z. Ivanova, E. Cernoskova, V. Vassilev, S. Boycheva, Mater. Lett. 57, 1025 (2003)

17. K. Hachiya, J. Non-Cryst. Solids 321, 217 (2003)

18. D. Vanderbilt, J. Joannopoulos, Phys. Rev. B 23, 2596 (1981)

19. T. Kanamori, Y. Terunuma, S. Takahashi, T. Miyashita, J. Non-Cryst. Solids 69, 231 (1985)

20. W. Lacourse, V. Twaddell, J. Mackenzie, J. Non-Cryst. Solids 3, 234 (1970)

21. J. S. Sanghera, V. Q. Nguyen1, P. C. Pureza, F. H. Kung, F. Miklos, L. Busse I. D. Aggarwal, SPIE's 1994 International Symposium on Optics, Imaging, and Instrumentation. 89(1994)

22. I. Haruvi-Busnach, J. Dror, N. I. Croitoru, Proc. SPIE 1228, Infrared Fiber Optics II, 85 (1990)

23. N. Croitoru, N. Shamir, J. Lightwave Technol. 5, 1637 (1987) 